\title{
OS PENSAMENTOS DÍSPARES DE WAGNER E NIETZSCHE ACERCA DA MÚSICA
}

Mayra Rafaela Closs Bragotto Barros Peterlevitz *

Resumo: Richard Wagner é um nome recorrente nas obras de Friedrich Nietzsche, d'O Nascimento da Tragédia a $O$ Caso Wagner, variando o tom das referências feitas ao compositor dos elogios esperançosos às críticas mordazes. A mudança na avaliação que o filósofo faz do compositor se evidencia após a ruptura na relação amistosa que foi mantida entre eles durante alguns anos, entretanto, em nossa visão, antes mesmo de se tornarem amigos, Wagner e Nietzsche sustentavam opiniões discordantes sobre diversos assuntos, como arte, política e religião. Vemos o rompimento como resultado da impossibilidade de se compatibilizarem suas opiniões de maneira ampla, sendo que neste trabalho gostaríamos de tratar especificamente o modo como o compositor e o filósofo pensavam a música, defendendo a ideia de que suas concepções eram distintas desde o início da amizade e que seus pensamentos continuaram a seguir caminhos díspares, apesar do intenso diálogo que mantiveram nos anos de convivência. Quando abordamos a música nas obras teóricas e artísticas de Wagner, é sempre presente sua relação com a palavra, não se restringindo o compositor a despertar sentimentos no ouvinte ou transmitir ideias apenas por meio de um discurso sonoro, mas também deixando explícitos quais conteúdos deveriam provocar a comoção do público por meio do discurso textual. Se a música não chega a ser colocada como serva da palavra, ela tampouco pode prescindir de sua companhia, havendo sempre este casamento entre som e texto. No conjunto dos escritos de Nietzsche, abordaremos a música especialmente as ideias da juventude, quando a música é pensada em meio às reflexões sobre a tragédia grega. Neste contexto, a música é soberana, não se submetendo às palavras e nem mesmo as aceitando em igualdade hierárquica; antes o som apenas "tolera" a seu lado o conceito, o qual é um delimitador, contrariando o poder libertador que a música deve exercer sobre o indivíduo. As diferentes concepções de Wagner e Nietzsche se refletem ainda no modo como cada um deles enfoca a arte trágica: o compositor se concentra no aspecto apolíneo da tragédia, enquanto o filósofo mais se atenta a seu lado dionisíaco.

Palavras-chave: Wagner, Nietzsche, Música

Em maio de 1869, na véspera do dia de Pentecostes, o jovem professor de Filologia Friedrich Nietzsche aguardava com ansiedade o momento de bater à porta de uma residência em Tribschen, onde visitaria o já renomado Richard Wagner. Contribuindo para a construção do relacionamento amistoso que ali principiava, interesses comuns garantiam longas horas de conversas: não apenas a música, assunto mais obviamente presente, mas também a filosofia antiga, os elementos apolíneo e dionisíaco na tragédia grega e o pensamento de Arthur Schopenhauer. Menos de uma década depois, o vínculo entre os amigos havia sido quebrado por Nietzsche, que - embora tenha ainda

\footnotetext{
*Universidade Federal de São Paulo. E-mail: mayra.violinista@gmail.com. Mestranda.
} 
escrito muito sobre Wagner até o fim de seu período de produtividade filosófica - não mais aceitou a convivência do compositor, o qual tentou reestabelecer o contato diversas vezes.

As ideias de Nietzsche são bastante conhecidas pelos estudiosos da filosofia, mas o pensamento de Wagner é ofuscado por sua magistral obra musical e por seu notório nacionalismo. Em nosso estudo, ao analisarmos a obra teórica wagneriana, tanto os escritos que versam sobre arte como os que tratam de outros temas, percebemos que as disparidades entre o ideário do compositor e do filósofo são bem anteriores à ruptura, precedendo o próprio início da amizade. Nesta comunicação, nosso ponto específico é a exposição de seus pensamentos acerca da música, mostrando sucintamente como cada um deles entendia esta arte na época em que se conheceram e nos anos subsequentes, além de comentarmos a perspectiva sob a qual enxergavam a tragédia grega, de forma a exemplificar nossa visão de que o fim da relação amistosa não limita a diferenças que surgiram ao longo dos anos de diálogo, mas tem como elemento fundamental a ênfase que gradativamente foi pesando sobre "discordâncias originárias".

Em 1851, Richard Wagner escreveu um texto intitulado Uma comunicação a meus amigos, visando esclarecer as modificações de seu pensamento que podem ser vistas no texto Ópera e Drama quando comparado com escritos e práticas anteriores:

eu compreendi completamente a linguagem da Música (...). O que é enunciável na linguagem da Música é limitado a sentimentos e emoções: ela expressa, em abundância, o que foi lançado à deriva de nossa linguagem em palavra (Wortsprache) em sua conversão a um mero órgão do intelecto, a saber, os conteúdos emocionais da linguagem puramente humana. O que assim permanece indizível na linguagem musical em si mesma é a definição exata do objeto do sentimento e da emoção por meio da qual eles adquirem uma significação mais certa. A amplitude e extensão da forma Musical da linguagem, conforme solicitado por este objeto, assim consiste na capacidade de poder delinear aguçada e distintamente o individual e o particular; e isso ela atinge somente ao ser casada à linguagem em palavra (tradução nossa) ${ }^{\dagger}$ ( 1892, p. 364).

A transmissão de um conteúdo "extra-musical" permaneceu como uma característica das composições wagnerianas à revelia das mudanças que ocorreram no pensamento do músico ao longo das décadas. Fazendo acompanhar uma mensagem verbal à música, Wagner almejou mais do que a comoção do público, desejando delimitar qual o "objeto" que deveria provocar os sentimentos do público. Embora o tempo tenha trazido modificações ao pensamento wagneriano, manteve-se firme em sua arte a relação entre a música e a palavra.

Para Wagner, a música carregaria uma mensagem de acordo com as ideias que o compositor sustentava no seu cotidiano. Assim, vemos, por exemplo, a expressão do amor livre no drama $A$ proibição de amar ou a Noviça de Palermo e, posteriormente, a exclusão de um canto de louvor a este mesmo amor livre do final de Crepúsculo dos Deuses. Do primeiro drama musical citado, finalizado em 1836, ao segundo, finalizado em 1874, mudou a visão de mundo de Wagner, cada vez mais próximo de convicções cristãs - sobre as quais não nos cabe deter neste momento, importando

\footnotetext{
† Na versão inglesa: "I had completely learnt the speech of Music (...) that which is utterable in the speech of Music, is limited to feelings and emotions: it expresses, in abundance, that which has been cast adrift from our Word-speech (Wortsprache) at its conversion into a mere organ of the Intellect, namely, the emotional contents of Purely-human speech. What thus remains unutterable in the absolute-musical tongue, is the exact definement of the object of the feeling and emotion, whereby the latter reach themselves a surer definition. The broadening and extension of the Musical form of speech (musikalischer Sprachausdruck), as called for by this Object, therefore consists in the attainment of the power to outline sharply and distinctly the Individual and the Particular; and this it gains alone by being wed to Word-speech".
} 
acentuar somente que a música para Wagner era também um meio de transmitir algo além de suas ideias puramente musicais, como a opção por certa harmonia ou a estruturação dos motivos musicais sob a forma da "melodia infinita" que caracteriza justamente o que o compositor nomeia drama musical. Isso não significa, como veremos, a subordinação total da música ao texto, ela não se tornou meramente um veículo para o compositor dar vazão ao pensador, mas ela também desempenhava esta função.

Porém, que o compositor concebesse a música ligada a uma mensagem verbal não habilita todas as histórias ao processo de musicalização, havendo uma seleção prévia, como Wagner esclarece:

eu não costumo escolher um assunto a esmo a fim de versificá-lo e então imaginar uma música adequada a ele (...). Não, meu método de produção é diferente disto: em primeiro lugar sinto-me atraído apenas por aqueles assuntos que se revelam não apenas poeticamente significativos, mas que tenham também um significado musical (MILLINGTON, 1995, p. 278).

Escolhida uma história com significado musical, a partir de sua adaptação pelo compositor seria produzida a partitura. Não devemos ignorar que Wagner não recorria à comum prática de encarregar um libretista da confecção da parte textual de suas obras, realizando ele próprio este trabalho. Assim, incorporava à vontade a uma "mensagem musical", mensagens filosóficas, morais e ideológicas. Os enredos serviriam ao drama musical por serem poética e musicalmente significativos, ao mesmo tempo em que passíveis de transmitir as opiniões e crenças de Wagner. Podemos trazer como exemplos o elogio à castidade que será visto em Parsifal (texto de 1857-1877/música de 18771882) ou mesmo Tristão e Isolda (texto 1854-1857/música de 1857-1859), história na qual temos os amantes que se unem misticamente na morte - sendo que esta narrativa interessou a Wagner justamente quando ele estava também interessado nas questões da abnegação e da renúncia (circa 1854), sob influência de Schopenhauer e o budismo. E quanto à saga mitológica dos Volsungos na tetralogia d'O Anel dos Nibelungos? Entendemos, grosso modo, estar diante de um caso à semelhança dos demais: significação poético-musical unida à capacidade de comunicar ao público as ideias extramusicais do compositor. Naturalmente, não queremos com isso diminuir os méritos da composição da colossal tetralogia, mas pensamos que havia em comum a todo trabalho wagneriano esta base na qual se relacionam a expressão de conteúdos em duas frentes.

E na obra de Friedrich Nietzsche, qual o tratamento dado à música? Aqui, nos restringiremos a seu primeiro livro, publicado em 1872, O Nascimento da Tragédia, cujos capítulos foram lidos e discutidos em primeira mão por Richard e Cosima Wagner. O jovem Nietzsche traz uma espetacular visão pessoal acerca dos gregos antigos, que no momento das representações trágicas se livrariam das amarras da racionalidade e das imposições sociais, entregando-se aos instintos e se deixando submergir no espírito trágico. Sobre estes episódios da vida grega, afirma:

a excitação dionisíaca é capaz de comunicar a toda uma multidão essa aptidão artística de ver-se cercado por uma tal hoste de espíritos com a qual ela, multidão, sabe interiormente que é uma só coisa. Esse processo do coro trágico é o protofenômeno dramático: ver-se a si próprio transformado diante de si mesmo e então atuar como se na realidade a pessoa tivesse entrado em outro corpo, em outra personagem. (2007, p. 56-57).

A música teria para Nietzsche uma função libertadora, transformando os homens em servidores do deus Dioniso, alheios ao tempo e às divisões instituídas pelos papéis desempenhados na organização social. Exatamente porque liberta, a música não deve impor aos ouvintes conteúdos delimitadores, ou petrificações do pensamento sob a forma de conceitos, ou lhes ditar "verdades" moralizantes. Junto à música os conceitos são meramente tolerados $(2007$, p. 48) e desempenham 
um papel específico: proteger o ouvinte da força massacradora que o som possui e que o tornaria insuportável aos homens se lhes fosse oferecido sem o acompanhamento da palavra.

Pode, contudo, parecer confusa a diferenciação do pensamento nietzschiano em relação ao de Wagner, se considerarmos que a tragédia tem a música acompanhada por uma história, surgindo a questão: se a tragédia, assim como os dramas wagnerianos sempre se faz acompanhar por um enredo, o que distingue as relações entre música e palavra na arte grega e na arte wagneriana? Não estaria, afinal, a tragédia a transmitir um conteúdo de modo análogo ao drama de Wagner? A resposta, para nós, reside além da simplificação que vê ambas as manifestações artísticas como casamentos entre som e libreto. Entendemos que, para Wagner, os enredos são mais autônomos em relação à arte: o compositor escolheria uma história que se mostrasse provida de certa "musicalidade", sendo passível de unir-se às suas concepções musicais, mas ele realizaria uma série de adaptações para que a história transmitisse conteúdos que eram parte de seu próprio escopo ideológico. Em seus dramas, não acreditamos que a música seja reduzida a serva da palavra, entretanto, nos parece haver uma equiparação na importância na função desempenhada por cada elemento nas composições. Por sua vez, o mito presente na tragédia, da forma como Nietzsche o entendia, era um componente importante, porém, aquém da música, a qual inclusive lhe incrementaria o significado, dotando-o de uma expressividade que de outro modo ele não possuiria: "aquilo que o poeta da palavra não alcançava, a suprema espiritualização e idealidade do mito, ele, como músico criador, podia conseguir a todos instante" (2007, p. 101). Unido à música, o mito passaria a expressaria mais do que os conceitos podem isoladamente transmitir.

Com estas considerações, expomos os pensamentos de Wagner e Nietzsche sem nos aventurarmos a julgar se o efeito obtido de fato pelo drama musical e a tragédia é condizente com as visões que o compositor e o filósofo possuíam destas artes - sendo lícito aos apreciadores formularem opiniões que, justificadamente, vejam teorias e práticas como incongruentes entre si. Reservamos neste ponto nossa interpretação pessoal à questão dos elementos dionisíaco e apolíneo na tragédia grega. O leitor minimamente familiarizado com a obra de Nietzsche percebe a relevância que o filósofo confere ao elemento dionisíaco, presente de modo muito relevante n'O Nascimento da Tragédia, obra na qual o tratamento dado ao apolíneo é mais restrito, sendo que não consideramos a disparidade fortuita, e sim deliberada. Menos conhecida do que o estudo nietzschiano é a dedicação de Wagner ao conhecimento e à reflexão sobre a tragédia grega. 0 compositor já escrevia sobre os elementos dionisíaco e apolíneo quando Nietzsche tinha seus quatro/cinco anos de idade. Em nossa visão, para Wagner foi o apolíneo que se destacou e marcou mais fortemente sua obra, pois ao conceber seus dramas musicais (ligados à ideia de obra de arte total), o compositor considera como um elemento fundamental de sua arte a forma como ela é visualmente transmitida, sendo imprescindível que sua música seja executada juntamente a uma representação visual adequada. Enquanto a tragédia, para Nietzsche, provocaria nos espectadores uma sensação de libertação e fusão da comunidade em um único espírito que celebra Dioniso, para Wagner, conforme percebemos pela aplicação de suas ideias sobre os gregos a suas composições, se trataria de apresentar um mundo muito bem caracterizado que o espectador seria convidado a visitar, mantendo-se, no entanto, afastado de qualquer displicência.

\section{Considerações Finais: "eu jamais ataco pessoas"}

Como dissemos inicialmente neste texto, acreditamos que Wagner e Nietzsche já se conheceram carregando os pensamentos díspares que ganhariam destaque crescente até culminarem na ruptura. Embora a exposição tenha sido breve e restrita apenas à música, esperamos que nosso ponto de vista tenha ficado claro. Antes de encerramos, gostaríamos de trazer algumas 
considerações sobre a destinação das críticas de Nietzsche. Entendemos que nem todos os apontamentos do filósofo que, à primeira vista, parecem ter como alvo o compositor devam ser lidas de tal forma. Em 1888, foram publicados tanto O Caso Wagner quanto Ecce Homo, sendo que esta obra lança luz a aspectos daquela. É de interesse notar o §7 da seção "Por que eu sou tão sábio":

eu jamais ataco pessoas - eu apenas me sirvo da pessoa como de uma poderosa lente de aumento, através da qual é possível tornar manifesta uma situação de necessidade comum, mas furtiva e pouco tangível (...). Foi assim que eu ataquei Wagner, ou, mais precisamente, a falsidade, o hibridismo instintivo de nossa "cultura", que confundia os refinados com os ricos, os tardios com os grandes (2012 b, p. 38).

Compreendemos que muitas das críticas nas quais figura o nome de Wagner, devem ser lidas parte dos ataques de Nietzsche a temas como à modernidade, ao nacionalismo, à moral cristã e o "fazer artístico" próprio do período romântico, como Nietzsche o entendia: "toda essa música do romantismo não foi, além disso, nobre o bastante, música o bastante, para se fazer valer em outros lugares que não o teatro e diante da multidão; ela foi de antemão música de segunda categoria, que pouco importava para verdadeiros músicos" (2012a, p. 191). Cabe notar que os dramas wagnerianos, os quais exigem uma superprodução para serem executados e foram pensados pelo compositor de forma a solicitar atenção total do público para sua apreciação podem ser tomados como ilustração para um fenômeno visto com preocupação pelo filósofo: o forte nacionalismo alemão. Wagner não escondeu em nenhum momento sua adesão - moldada por idiossincrasias, note-se - à causa da unificação da Alemanha e suas obras principais têm efeito análogo ao sentimento nacionalista, segundo nossa interpretação do texto nietzschiano. Do mesmo modo como o compositor desejava que seus espectadores se sentissem imersos na experiência de apreciação de seus dramas musicais, o nacionalismo envolveria o povo de tal modo que ele se fecharia a outros estímulos. Ademais, não devemos nos esquecer de que Wagner buscou forjar com suas obras uma identidade cultural para a Alemanha, antes dominada pelas óperas italianas e, especialmente, francesas. Quando Nietzsche diz, em O Caso Wagner: "ah, esse velho Minotauro! O que já nos causou! A cada ano são levados cortejos das mais belas jovens e rapazes ao seu labirinto, para que ele os devore - a cada ano a Europa inteira

entoa: 'para Creta! para Creta!'” (p. 38), vemos uma referência clara ao Festival de Bayreuth, pensado por Wagner como um acontecimento cultural que deveria ser prestigiado por todo o povo alemão, indistintamente, e à dominação das produções wagnerianas na programação dos demais teatros alemães, havendo praticamente um espelhamento na difusão das obras de Wagner e no sentimento nacionalista.

\section{Bibliografia}

DIAS, Rosa Maria. Amizade estelar: Schopenhauer, Wagner e Nietzsche. Rio de Janeiro: Imago, 2009.

MILLINGTON, Barry (Org.). Wagner, um compêndio. Rio de Janeiro: Jorge Zahar Editor, 1995.

NIETZSCHE, F. Além de bem e mal: prelúdio a uma filosofia do futuro. Porto Alegre: L\&PM, 2012a. 
O Caso Wagner ; Nietzsche contra Wagner. 2ª reimpressão. São Paulo: Companhia das Letras, 2009.

O Nascimento da Tragédia ou Helenismo e Pessimismo. São Paulo: Companhia das

Letras, 2007.

WAGNER, R. A communication to my friends. In: Richard Wagner's Prose Works - Volume 1: The Art-Work of the Future. Trad. William Ashton Ellis. Londres: Kegan, Paul, Trench, Trübner \& Co., Ltd., 1892, p. 267-392.

Art and Revolution, with Introduction. In: Richard Wagner's Prose Works - Volume 1: The Art-Work of the Future. Trad. William Ashton Ellis. Londres: Kegan, Paul, Trench, Trübner \& Co., Ltd., 1892, p. 267-392.

. Das Kunstwerk der zukunft. In: Gesammelte Schriften und Dichtungen - Volume 3.

Leipzig: Berlag von C. W. Fribsch, 1872, p. 51-210. 